\title{
Editorial
}

\section{Recent Advances in Borehole Geophysics in Unconventional Resources: Applications, Techniques and Challenges}

\author{
Hua Wang ${ }^{* \$}$
}

State Key Laboratory of Petroleum Resources and Prospecting, China University of Petroleum, Beijing, China

\section{INTRODUCTION}

More percentage of new productions in oil industry is from unconventional oil and gas such as oil shale, tar sand, laminated sand, tight oil (siltstone), tight gas, gas hydrate, and igneous rock, because the conventional oil and gas can no longer meet the need of the world. Researchers in response pay more attentions to the unconventional resources. Formation properties such as total organic carbon (TOC), porosity, permeability and saturation are critical for exploration and development of the unconventional reservoirs. Recent developments in wire-line methods to determine these properties have led to the completion and production strategies based on those mentioned properties. Logging-WhileDrilling measurements have the capability of determining some of these properties in real-time, so that completion decisions can be made rapidly and wells can be steered using the real-time data [1].

The borehole geophysics technologies, mainly applied for the unconventional reservoir, have also played important roles during the exploration and development. Formation evaluation (FE) while drilling for instance is an established technique in horizontal well orientations for unconventional reservoirs. Real-time data and rapid analysis provide rock parameters that would impact completion decisions. The nuclear magnetic resonance (NMR) logging could tell the different fluid composites of the shale. Innovations in LWD NMR enable quantification of porosity, irreducible and clay bound water in real-time. The elastic parameters of the formation, the fractures outside of the borehole, and even the brittleness during the hydraulic fracturing would be determined by the acoustic logging data, especially from the acoustic logging-while drilling and the borehole remote reflection or imaging [2-6]. The images from borehole acoustic reflection imaging and electronic imaging provide input for geo-mechanical models that are used to plan or optimize the wellbore stabilization and stimulation treatments. Evaluation of the performance of reservoir stimulation by hydrofracturing is critical for shale gas and tight sandstone

\footnotetext{
*Address correspondence to this author at the Earth Resources Laboratory at Massachusetts Institute of Technology, Cambridge, Massachusetts, USA; Tel: +1-617-253-0950; Fax: +1-617-253-6385;

E-mail: wanghuaupc@126.com

\$Guest Editor
}

reservoirs. We usually use the micro-seismicity monitoring on surface and/or down hole to evaluate the performance of hydro-fracturing and distribution of the induced fractures [7]. The down-hole monitoring of the micro-seismic induced by the hydraulic fracturing in shale layer would be carried out by the different systems of receivers in the borehole, such as distributed acoustic system (DAS) or three-components down-hole receivers. Distributed acoustic sensing technique (DAS) can be applied in hydraulic fracturing monitoring (micro-seismic), VSP and other related aspects. The widely application of DAS can significantly lower the cost and provide with more comprehensive and consecutive data for the technical support of the elaborated delineation and development of unconventional oil \& gas. Some other methods in borehole geophysics such as formation tester in both openhole and cased-hole, and electronic logging would help us to understand the properties such as the pressure and porosities of the shale and tight sandstone formations [8]. With the development of remote acoustic imaging method, the investigate depth of acoustic logging can reach more than 20 meters outside of the borehole wall, which extend the ability of acoustic logging to detect the fracture induced by hydrofracturing.

This thematic issue is focusing on the borehole geophysics on unconventional oil and gas, including the applications, techniques and challenges of the recent advances in borehole geophysics in shale gas, tight gas reservoirs. The proposal of this issue was addressed in May 2014 and by a call for paper submission in September 2014. After peer-reviewing and revision more than a half year, twelve papers are selected and accepted aiming for the thematic issue. These papers integrate a variety in borehole geophysics such as data interpretation for permeability and saturation, identification of diagenetic facies, the pore-pressure determination and hydrofracture related technologies in shale and tight gas reservoirs.

\section{APPLICATION}

Shi et al. propose a fast interpretation method for shale gas reservoir in "A Cross-plot for Mud Logging Interpretation of Unconventional Gas Shale Reservoirs and Its Application". Using gas and mud logs, they establish a cross-plot of the drilling time ratio and hydrocarbon contrast coefficient. The cross-plot can directly identify and evaluate the fluid properties in the apparent gas layer, especially in the oil 
and gas zone with weak identification. Good field applications have taken place in Jianghan oilfield in Middle China.

Xu et al. study the reservoir-caprock assemblage and estimate the productivity of unconventional oil and gas by dual logging parameter method in "Study on Reservoir-caprock Assemblage by Dual Logging Parameter Method". Due to the strong heterogeneous feature of tight sandstone reservoirs, to determination of the permeability is hard. Their work has influenced the evaluation of the productivity and the development plan.

Zhu et al. use the diagenetic comprehensive coefficient to determine the permeability of tight sandstone reservoir in "Permeability Prediction of Tight Sandstone Reservoirs Using Improved BP Neural Network". They use a modified BP neural network algorithm to improve the evaluation accuracy of permeability.

Ge et al. (paper "Predicting the Relative Permeability of Water Phase Based on Theory of Coupled ElectricitySeepage and Capillary Bundle Model") provide an improved method to predict the relative permeability of water phase with the aid of petro-physical data such as saturation index. Their work makes the reservoir model more suitable for unconventional resources such as tight oil and shale gas, since the relative permeability of different phases is difficult to obtain by conventional steady and unsteady experiments. Transportation of the fluid in pores for unconventional resources can be easily depicted by the new model.

Yu et al. (paper "An identified method for lacustrine shale gas reservoir lithofacies using logs: A case study for No.7 section in Yanchang formation in Ordos basin") and Zhu et al. (paper "Types of Diagenetic Facies of Tight Sandstone Reservoir and Its Quantitative Identification by Well Log Data") combine multiple logs into a single or two $\log \mathrm{s}$ without losing information using the Principal component analysis (PCA) method to reduce the dimension of multidimensional data. The dimension reducing method is helpful for overcoming the difficulties in the determination of facies from various logs. Then the facies can be used as an important control factors in the tight sandstone and shale gas reservoirs development and a comprehensive performance indicator for diagenesis and prediction of "dessert" of tight sandstone and shale gas reservoirs. The two papers use the combined curves to calculate the multi-well tops correlation for regression analysis, and then use the decision tree method to obtain lithofacies identification. In the paper of $\mathbf{Y u}$ et al., they consider exploration and development as integrated procedure, where they combine the well logging and statistics methods to identify the lithofacies. They give lacustrine shale gas reservoir in Ordos basin Yanchang formation $7^{\text {th }}$ section as an example. Zhu $\boldsymbol{e t}$ al. also gives some field cases for tight sandstone reservoirs.

Hao and Jin (paper "Logging Evaluation Method for Pore Pressure of Shale Gas Reservoirs-Taking Fuling Area, Sichuan Basin as an Example") analyze different calculation methods for pore-pressure by using logging data, and then applied them into the study of unconventional reservoirs. Based on the data, they proposed an "equivalent depth method" and applyied the method to field data from Fuling area, where the most high productivity shale gas reservoir is located in in China. They obtain a good prediction result in Fuling area and their study would guide the hydrofracturing design.

\section{TECHNIQUES}

Wei et al. (paper "Directional P-wave Remote Acoustic Imaging in an Acoustically Slow Formation") discuss the directional P-wave remote acoustic imaging in an acoustically slow formation (such as shale formation) to improve dipole remote acoustic applications. They demonstrate its sensitivity and feasibility in conjunction with a numerical simulation of $\mathrm{P}$-wave remote acoustic imaging. Based on the theoretical analysis, a field example is used to demonstrate these characteristics and the application effectiveness of dipole-generated P-wave imaging and monopole-generated $\mathrm{P}$-wave imaging.

Li et al. (paper "Current and Future Applications of Distributed Acoustic Sensing as A New Reservoir Geophysics Tool') give a review on the measuring principles, advantages, field applications of DAS and the corresponding preprocessing methods as well as the limitations that hinder its applications in exploration and production. In addition, future developments for DAS are discussed, including the enhancement of $\mathrm{S} / \mathrm{N}$ ratio, precise determination of receiver channels in depth, rapid processing of massive data and integrated interpretation of multi-mode optical fiber.

Ni et al. (paper "Feasibility Study of While-drilling Data Transmission Technology Based on Radio Frequency Identification") propose a novel while-drilling data transmission technique based on Radio Frequency Identification (RFID). As we know, with the new technologies being used, such as Logging-While-Drilling (LWD), more engineering and geological data are needed to collect in the unconventional reservoir. However, down-hole data transmission especially in LWD case is still a bottleneck for real-time applications. They consider a large amount of data that can be transmitted to the ground by RFID while drilling. Both the transmission speed and real-time are investigated. The equipment with improved performance would benefit the exploration and development of unconventional oil and gas resources.

\section{CHALLENGES}

Zhang et al. give us a review paper "Review of Well Logs and Petrophysical Approaches for Shale gas in Sichuan Basin, China", in which they review the status of application of logs for shale gas reservoir analyze and the typical logs characteristics of the gas-bearing shale. In the end, they discuss the application of petrophysical methods in the shale gas exploration and development in the Sichuan Basin.

Tan et al. (paper "The Key and the Countermeasures Research of Shale Gas Fracturing Technology") summary the difficulties and related technologies on shale gas exploitation, especially the problem definition, scope of application, characteristics and development direction. They also analyze the relative solutions about the fracturing fluid manufacture, selection and improvement of the fracturing fluids, fractures extension, equipment performance, pressure test, fracturing effect evaluation and reservoir protection. Based on the shale gas geological and technical characteristics of the United 
States, they look forward to the direction of the development of shale gas in China.

\section{REFERENCES}

[1] R.A. Meador, "Logging-while-drilling. A story of dreams, accomplishments, and bright futures", In: Society of Petro-physicists and Well-Log Analysts $50^{\text {th }}$ Annual Logging Symposium, 2009.

[2] G. Tao, F. He, B. Wang, H. Wang, and P. Chen, "Study on 3D simulation of wave-fields in acoustic reflection image logging", Science China, Series D, vol. 51, no. 2, pp. 186-194, 2009.

[3] H. Wang and G. Tao, "Wavefield simulation and data-acquisitionscheme analysis for LWD acoustic tools in very slow formations", Geophysics, vol. 76, no. 3, pp. E59-E68, 2011.

[4] H. Wang, G. Tao, and K. Zhang, "Wavefield simulation and analysis with the finite-element method for acoustic logging while drill- ing in horizontal and deviated wells", Geophysics, vol. 78, no. 6, pp. D525-D543, 2013.

[5] X. Jin, S.N. Shah, J.A. Truax, and J.C. Roegiers, "A Practical Petrophysical Approach for Brittleness Prediction from Porosity and Sonic Logging in Shale Reservoirs", Society of Petroleum Engineers, 170972, 2014.

[6] X. Fang, A. Cheng, and M.C. Fehler, "Investigation of borehole cross-dipole flexural dispersion crossover through numerical modeling”, Geophysics, vol. 80, no. 1, pp. D75-D88, 2015.

[7] X. Zeng, H. Zhang, X. Zhang, H. Wang, Y. Zhang, and Q. Liu, "Surface microseismic monitoring of hydraulic fracturing of a shale-gas reservoir using short period and broadband seismic sensors", Seismological Research Letters, vol. 85, no. 3, pp. 668-677, 2014.

[8] T.S. Collett, "Gas Hydrate Reservoir Properties", Society of Petroleum Engineers, 168760, 2013.

Received: March 03, 2015

Revised: March 18, 2015

Accepted: April 04, 2015

() Hua Wang; Licensee Bentham Open.

This is an open access article licensed under the terms of the Creative Commons Attribution Non-Commercial License (http://creativecommons.org/licenses/by-nc/3.0/) which permits unrestricted, non-commercial use, distribution and reproduction in any medium, provided the work is properly cited. 